\title{
LA PERTENENCIA A LA UNIÓN EUROPEA Y SU REPERCUSIÓN EN LA RESPONSABILIDAD PATRIMONIAL
}

\author{
E. Cobreros Mendazona \\ Catedrático de Derecho Administrativo \\ Universidad del País Vasco
}

A la memoria de Jesús Leguina*

\begin{abstract}
RESUMEN
La pertenencia a la Unión Europea también ha tenido su repercusión en el ámbito de la responsabilidad patrimonial del Estado. Se analizan aquí, en primer lugar, el principio de la responsabilidad patrimonial de los Estados miembros frente a los particulares perjudicados por causa de su incumplimiento del derecho de la Unión y, en segundo lugar, su incidencia efectiva en nuestro ordenamiento.
\end{abstract}

Palabras clave: incumplimiento del derecho de la Unión Europea; responsabilidad patrimonial del Estado.

\begin{abstract}
The European Union membership has had impact on the field of State liability. Here, we first analyze the principle of pecuniary liability of Member States vis a vis individuals impaired by the breach of the European Union Law and second its actual incidence in our legal order.
\end{abstract}

Key words: breach of EU Law; State Liability.

"La infausta noticia de su fallecimiento llegó vencida ya la tarde del pasado 14 de mayo. Algunos aún no hemos podido reponernos del dolor que nos produjo. 


\section{SUMARIO}

I. EL PANORAMA DE LA RESPONSABILIDAD PATRIMONIAL «INTERNA» Y LAS REPERCUSIONES DE LA CONDICIÓN DE ESTADO MIEMBRo DE LA UNIÓN EUROPEA.-II. LA RESPONSABILIDAD PATRIMONIAL DE LOS ESTADOS POR SU INCUMPLIMIENTO DEL DERECHO DE LA UNIÓN EUROPEA: 1. Su inicial establecimiento como principio inherente al sistema del Tratado (1991). 2. La construcción definitiva del principio (1996). 3. La extensión del principio al difícil ámbito del incumplimiento judicial del derecho de la Unión Europea (2002). 4. Relevancia del principio de la responsabilidad patrimonial de los Estados por su incumplimiento del derecho de la Unión Europea.-III. LA REPERCusIón DE ESTE PRINCIPIO EN NUESTRO SISTEMA DE RESPONSABILIDAD: 1. Su efectiva aplicación por la jurisdicción contencioso-administrativa. 2. Una cuestión que ha planteado y solucionado el principio de equivalencia: la inicial diferencia de requisitos procedimentales para la indemnización de los daños causados por una ley inconstitucional y por una ley contraria al derecho de la Unión Europea. 3. La discutida exigencia del requisito de la violación suficientemente caracterizada. 4. La regulación legal establecida por la Ley del Régimen Jurídico del Sector Público.

I. EL PANORAMA DE LA RESPONSABILIDAD PATRIMONIAL «INTERNA» Y LAS REPERCUSIONES DE LA CONDICIÓN DE ESTADO MIEMBRO DE LA UNIÓN EUROPEA

En nuestro derecho público y, destacadamente, en el derecho administrativo el sistema de responsabilidad patrimonial es una pieza clave del funcionamiento estatal. Su previsión a partir de las leyes de los años cincuenta y el posterior desarrollo efectivo de sus posibilidades - gracias a una sólida doctrina que incidió sobre el aspecto de la garantía que supone frente al actuar de la Administración (entre la que podemos destacar a García de Enterría y T. R. FERnÁndez, a Leguina, a Martín REBOLlo y a tantos más) y gracias a una jurisdicción contencioso-administrativa que, atenta y sensible a tal doctrina, supo construir paulatina pero resueltamente un sólido cuerpo de jurisprudencia-, debe reconocerse como un valioso y avanzado componente de nuestro ordenamiento público.

En clave exclusivamente interna, este panorama - asentado sobre la más firme base del art. 106.2 CE— ha ido sufriendo la lógica evolución al hilo de las diversas aplicaciones que nuestro sistema de responsabilidad administrativa directa y objetiva iba experimentando. De tal manera que ha devenido un sistema útil y predecible, sin perjuicio de que también se hayan comenzado a escuchar algunas voces críticas con respecto a una (posible e indeseada) "generosidad» excesiva del mismo ${ }^{1}$, a lo que qui-

1 Lo ha planteado con precisión O. Mir PuigPelat (2002), La responsabilidad patrimonial de la Administración (Hacia un nuevo sistema), Madrid: Civitas, con prólogo de E. GARCíA DE ENTERRÍA. 
zá responda la paulatina admisión jurisprudencial de un cierto margen de tolerancia, sobre todo en el ejercicio de potestades discrecionales. Y sin perjuicio, asimismo, de algunas peculiaridades o especificidades que iban detectándose en determinados ámbitos, como puede ser, por ejemplo, el de la responsabilidad sanitaria, donde se puede apreciar, por un lado, cierto rigor al exigir un comportamiento no amparado por la lex artis ni por el nivel de los conocimientos o de la técnica, y, por otro lado, la introducción de un novedoso (entre nosotros) concepto indemnizatorio, como es el de la pérdida de oportunidad (sanitaria, en el caso) ${ }^{2}$.

A esto hay que añadir la introducción de la responsabilidad estatal por error judicial, por prisión provisional indebida (como especie del anterior) y por el funcionamiento anormal de la Administración de Justicia, que comenzó a materializarse a partir de la entrada en vigor de la Ley Orgánica del Poder Judicial, en 1985, que posibilitó las previsiones contenidas en el art. $121 \mathrm{CE}$.

Finalmente, tenemos que incluir la conocida como responsabilidad del Estado legislador, que — sin respaldo constitucional expreso, aunque con su (limitada) admisión, en la Ley de Régimen Jurídico y del Procedimiento Administrativo Común de 1992- surgió en nuestro sistema de responsabilidad por la resuelta actuación de la Sala Tercera del Tribunal Supremo, a partir sobre todo del año 2000, en relación con las leyes inconstitucionales.

Pues bien, este conjunto se verá afectado por las implicaciones jurídicas que conlleva nuestra pertenencia a la Unión Europea con la aparición de un nuevo título de imputación, irradiado desde el derecho supranacional, como es el de la responsabilidad por el incumplimiento del derecho de la Unión Europea.

Sucede además que, así como los grandes principios jurídicos en los que se basa la relación entre el ordenamiento de la Unión y el de los Es$\operatorname{tados}^{3}$ - como son, destacadamente, la eficacia directa ${ }^{4}$, la primacía ${ }^{5}$ o la interpretación conforme ${ }^{6}$ - ya estaban acuñados por el Tribunal de Justicia en el momento de nuestra entrada efectiva en las Comunidades

2 Desde hace tiempo vienen haciendo un exhaustivo y riguroso seguimiento de la jurisprudencia recaída en materia de responsabilidad patrimonial pública LóPEz MENUdo, CARRILLO DonaIRe y Guichot (en la actualidad, este último en solitario), primero en Justicia Administrativa y después en Revista Española de Derecho Administrativo (Crónicas de Jurisprudencia).

3 Para una visión general, valga con la remisión a R. Alonso García (2014), Sistema Jurídico de la Unión Europea, Cizur: Civitas-Thomson Reuter, $4^{\mathrm{a}}$ ed., espec. págs. 275 y ss. y A. MANgas Marín y D. Liñán Nogueras (2012), Instituciones y Derecho de la Unión Europea, Madrid: Tecnos, $7^{\mathrm{a}}$ ed., espec. págs. 385 y ss.

4 A partir de la Sentencia de 5 de febrero de 1963, as. Van Gend \& Loos, 26/62.

5 A partir de la Sentencia de 15 de julio de 1964, as. Flaminio Costa, 6/64.

6 A partir de la Sentencia de 10 de abril de 1984, as. Von Colson y Kaumann, 14/83. 
Económicas Europeas, no pasaba lo mismo con el principio de la responsabilidad patrimonial de los Estados, que no surgirá hasta finales de 1991.

En el siguiente apartado veremos, muy sintéticamente ${ }^{7}$, el proceso de gestación de este nuevo supuesto de responsabilidad patrimonial -originado en el derecho supranacional y consolidado jurisprudencialmente en una decena de años- que se introducirá de manera inexorable en todos los ordenamientos estatales.

II. LA RESPONSABILIDAD PATRIMONIAL DE LOS ESTADOS POR SU INCUMPLIMIENTO DEL DERECHO DE LA UNIÓN EUROPEA

1. Su inicial establecimiento como principio inherente al sistema del Tratado (1991)

Como tantos otros aspectos decisivos para el derecho de la Unión Europea, la responsabilidad patrimonial del Estado incumplidor de las obligaciones que establece el derecho de la Unión es un producto del genio creativo del Tribunal de Luxemburgo y tiene una fecha de nacimiento bien precisa: la Sentencia Francovich ${ }^{8}$.

El establecimiento explícito de la responsabilidad patrimonial del Estado incumplidor se establece, inicialmente, a partir de un auténtico «agujero negro» del derecho de la Unión Europea, como era el incumplimiento por un Estado de su obligación de desarrollar o incorporar debidamente a su ordenamiento el contenido de una Directiva. De tal manera que, en el caso, la inactividad del Estado italiano había tenido la consecuencia de frustrar el goce de los derechos que la Directiva obligaba a incluir en los ordenamientos estatales en beneficio de los trabajadores. Ante esta situación de «impotencia» para la efectiva aplicación del derecho de la Unión Europea, el Tribunal de Justicia dará el paso decisivo en la cuestión que nos ocupa desplegando la siguiente argumentación:

a) si, por un lado, «la plena eficacia de las normas comunitarias se vería cuestionada y la protección de los derechos que reconoce se debilitaría si los particulares no tuvieran la posibilidad de obtener una repara-

\footnotetext{
7 Para mayores precisiones, permítase la remisión a E. Cobreros Mendazona (2015), Responsabilidad patrimonial del Estado por incumplimiento del Derecho de la Unión Europea, Madrid: Iustel, espec. a su Parte Primera, págs. 21 a 126.

8 De 19 de noviembre de 1991, asuntos acumulados C-6/90 y 9/90, dictada por el Pleno en cuestión prejudicial interpretativa solicitada por sendos juzgados italianos. Aunque es conveniente advertir inmediatamente que esta Sentencia no será la construcción completa y definitiva.
} 
ción cuando sus derechos son lesionados por una violación del derecho comunitario imputable a un Estado miembro» (aptdo. 33);

b) y si, por otro lado, "la posibilidad de reparación a cargo del Estado miembro es particularmente indispensable cuando, como ocurre en el presente asunto, la plena eficacia de las normas comunitarias está supeditada a la condición de una acción por parte del Estado y, por consiguiente, los particulares no pueden, a falta de tal acción, invocar ante los órganos jurisdiccionales nacionales los derechos que les reconoce el derecho comunitario» (aptdo. 34);

c) la rotunda conclusión será que «el principio de la responsabilidad del Estado por daños causados a los particulares por violaciones del derecho comunitario que le son imputables es inherente al sistema del Tratado» (aptdo. 35).

De esta manera tan lineal y, en apariencia, sencilla quedará entronizado ex novo en el derecho de la Unión Europea el principio de la responsabilidad patrimonial (extracontractual) de los Estados, debiendo insistirse en el carácter de principio propio del derecho de la Unión y, por lo tanto, indisponible para los Estados; de tal manera que desde los ordenamientos estatales ni podrá eludirse o suprimirse, ni podrán establecerse otros requisitos adicionales para su materialización.

La S. Francovich enuncia con carácter general el principio y establece tres requisitos - necesarios y suficientes, se insiste- para generar indemnización en beneficio del perjudicado: «El primero de estos requisitos es que el resultado prescrito por la Directiva implique la atribución de derechos a favor de los particulares. El segundo requisito es que el contenido de estos derechos pueda ser identificado basándose en las disposiciones de la Directiva. Por último, el tercer requisito es que exista una relación de causalidad entre el incumplimiento de las obligaciones que incumben al Estado y el daño sufrido por las personas afectadas» (aptdo. 40).

Pero si los requisitos materiales vienen establecidos por el derecho de la Unión Europea ${ }^{9}$, el ejercicio efectivo de la acción indemnizatoria contra el Estado habrá de hacerse en el marco del derecho estatal en materia de responsabilidad y, por lo tanto, en último término a garantizar por los tribunales nacionales. Remisión que irá acompañada siempre de la cautela que implican los principios (también de derecho de la Unión Europea) de efectividad y equivalencia.

9 El derecho a la indemnización «está basado directamente en el derecho comunitario», se encarga de enfatizar esta Sentencia (aptdo. 41). 


\section{La construcción definitiva del principio (1996)}

Antes de pasados cinco años desde la S. Francovich, el Tribunal de Justicia dicta un destacadísimo pronunciamiento, como es la Sentencia Brasserie du Pêcheur y Factortame ${ }^{10}$. Se trataba en ella de confrontar si el principio de la responsabilidad estatal regía también en el supuesto de un incumplimiento atribuible directamente al Parlamento «soberano» de un Estado. La Sentencia entra de lleno en los problemas de la responsabilidad estatal por incumplimiento y expresa el principio fundamental y elemental común a todos los ordenamientos de los Estados, que le servirá de sólido punto de partida: «una acción u omisión ilegal produce la obligación de reparar el perjuicio causado", lo que considera extensible también a los supuestos en los que son los poderes públicos los que originan el daño (aptdo. 29).

Así, el Tribunal de Justicia sostendrá que el principio de la responsabilidad estatal resulta aplicable en cualquier supuesto de violación del derecho de la Unión por parte de un Estado, explicitando además que tal responsabilidad surge «independientemente de cuál sea el órgano del Estado miembro a cuya acción u omisión se deba el incumplimiento» (aptdo. 32), con lo que la obligación resarcitoria tendrá lugar también - acabará diciendo - cuando el incumplimiento dañoso «sea atribuido al legislador nacional» (aptdo. 36).

Hay dos aspectos de esta Sentencia que conviene destacar ahora separadamente:

A) El primero es la incorporación del requisito de la violación suficientemente caracterizada

La S. Brasserie modifica en un punto capital la construcción efectuada en la S. Francovich - debido probablemente a las críticas de incoherencia que se le habían formulado a ésta- y trae a colación la experiencia habida con respecto a la responsabilidad extracontractual de las instituciones de la propia Unión, prevista en el art. 340 TFUE. Así, dirá que «los requisitos para que exista la responsabilidad del Estado por los daños causados a los particulares por la violación del derecho comunitario no deben, a falta de justificación específica, diferir de los que rigen la responsabilidad de la Comunidad en circunstancias comparables. En efecto, la protección de los derechos que los parti-

10 De 5 de marzo de 1996, asuntos acumulados C-46/93 y 48/93, dictada por el Pleno del Tribunal. 
culares deducen del derecho comunitario no puede variar en función de la naturaleza nacional o comunitaria de la autoridad que origina el daño» (aptdo. 42) ${ }^{11}$.

Esta homogeneización de régimen de la responsabilidad extracontractual por incumplimiento del derecho de la Unión Europea -que conduce a que resulte indiferente que corresponda la obligación resarcitoria a la Unión o a un Estado miembro- acarrea la incorporación al régimen de la responsabilidad estatal del requisito de la «violación suficientemente caracterizada» del derecho de la Unión Europea ${ }^{12}$. Lo que significa que no cualquier infracción del ordenamiento de la Unión originará la obligación de indemnizar, sino sólo aquella que reúna esta característica, precisamente, que es equivalente a una violación manifiesta y grave del derecho de la Unión Europea ${ }^{13}$.

Ante la evidente indeterminación del requisito de la violación suficientemente caracterizada, el propio Tribunal de Justicia consideró conveniente aportar algunos elementos de clarificación para que, cuando los órganos jurisdiccionales estatales conozcan de una reclamación de este tipo, puedan aplicar correctamente este presupuesto. Tales elementos a tener en cuenta son: a) el grado de claridad y de precisión de la norma vulnerada, b) la amplitud del margen de apreciación que la norma infringida deja a las autoridades nacionales, c) el carácter intencional o involuntario de la infracción cometida o del perjuicio causado, d) el carácter excusable o inexcusable de un eventual error de derecho y e) la circunstancia de que las actitudes adoptadas por una institución de la Unión Europea hayan podido contribuir a la omisión, la adopción o el mantenimiento de medidas o de prácticas nacionales contrarias al derecho de la Unión (aptdo. 56) ${ }^{14}$.

11 Algo más tarde, esto mismo se sostendrá también desde la "otra perspectiva», es decir, para aplicar al régimen de la responsabilidad extracontractual de las Instituciones de la Unión Europea lo establecido en los casos de responsabilidad de los Estados, con lo que la duplicidad de sistemas se reconducirá definitivamente a la unidad. Véase la Sentencia de 4 de julio de 2000, as. Bergaderm, C-352/98P. En esta Sentencia, dictada en un recurso de responsabilidad contra la Comisión, el Tribunal de Justicia reitera (en casación) lo que se acaba de recoger, pero esta vez, como se ha señalado, en el otro sentido.

12 Sobre este decisivo (y discutido) concepto jurisprudencial, valga la remisión a E. GUIснот Reina (2001), La responsabilidad extracontractual de los poderes públicos según el Derecho Comunitario, Valencia: Tirant lo Blanch, págs. 230 y ss., 314 y ss. y, sobre todo, 495 y ss.

13 Como el propio Tribunal de Justicia se encarga de señalar, recordando su asentada jurisprudencia sobre la responsabilidad extracontractual de las Instituciones de la Unión: «sólo incurre en responsabilidad si la institución de que se trata se ha extralimitado, de manera manifiesta y grave, en el ejercicio de sus facultades» (S. Brasserie, cit., aptdo. 45).

14 Este concepto de la violación suficientemente caracterizada no ha sido posteriormente determinado con mayores precisiones, además del ya mencionado carácter de «manifiesto" y «grave», sino simplemente reiterado ad nauseam. A lo más, podrían citarse algunos pronunciamientos del Tribunal General, en recursos por indemnización contra la Unión —o sea, ex art. 340 TFUE (por remisión del art. 268 TFUE), pero que ya se ha visto cómo el Tribunal de Jus- 
En la S. Brasserie se efectúa también una aportación (que se mantiene vigente desde entonces, sin variación), cual es la de establecer claramente que siempre habrá una violación suficientemente caracterizada en los siguientes supuestos: $1^{\circ}$ ) cuando el incumplimiento hubiera perdurado a pesar de haberse dictado una Sentencia que declare la existencia del incumplimiento estatal (ex art. 260 TFUE); $2^{\circ}$ ) cuando el incumplimiento hubiera perdurado a pesar de haber una Sentencia prejudicial interpretativa de la que se deduzca el incumplimiento; y $3^{\circ}$ ) cuando existiera una jurisprudencia reiterada en la materia, de la que resulte el carácter de infracción del comportamiento estatal en cuestión.

La finalidad a la que responde esta creación jurisprudencial del requisito de la violación suficientemente caracterizada no es otra - como, por lo demás, resulta evidente- que restringir o limitar los supuestos indemnizatorios. Dicho más directamente, se trata de salvaguardar la posibilidad de casos en los que, pese a producirse y constatarse un incumplimiento (en nuestro caso, de un Estado miembro; anteriormente, sólo de una institución de la Unión Europea), el daño originado no tenga que ser resarcido. En definitiva, se trata de admitir o reconocer un cierto margen de tolerancia frente a la ilegalidad, que implica la no resarcibilidad de algunas actuaciones u omisiones ilegales dañosas.

Y la justificación de esta opción puede presentar alguna dificultad, ya que el Tribunal de Justicia no la ha explicitado nítidamente, en el caso de la responsabilidad de los Estados miembros, sino que - por la tan reiterada unificación de sistema de responsabilidad extracontractualtenemos que deducirla de las razones que en su momento fundamentaron (y siguen haciéndolo en lo esencial) esta restricción en favor de las instituciones de la Unión ${ }^{15}$.

Queda claro, entonces, el motivo que ha llevado al Tribunal de Luxemburgo a introducir el requisito de la cualificación de la ilegalidad

ticia ha interpretado que debe compartir régimen jurídico con el caso que aquí nos ocupa-, que consideran cumplido el requisito de la violación suficientemente caracterizada cuando se compruebe «una irregularidad que no habría cometido una administración normalmente prudente y diligente que estuviera en las mismas circunstancias», Sentencia de 12 de julio de 2001, as. Comafrica, T-198/95, 171/96, 230/97, 174/98 y 225/99, aptdos. 138 y 149, reiterado con posterioridad en otras varias.

15 En palabras del Tribunal General para referirse a la responsabilidad ex art. 340 TFUE, el requisito de una violación suficientemente caracterizada «pretende, cualquiera que sea la naturaleza del acto ilícito de que se trate, evitar que el riesgo de tener que cargar con las indemnizaciones de los daños alegados por las personas interesadas menoscabe la capacidad de la institución de que se trate de ejercer plenamente sus competencias en vista del interés general, tanto en el marco de su actividad normativa o que implique decisiones de política económica como en la esfera de su competencia administrativa, sin que recaigan sobre terceros, no obstante, las consecuencias de incumplimientos flagrantes e inexcusables», Sentencia de 23 de noviembre de 2011, as. Sison III, T-341/07, aptdo. 34; y, en idéntico sentido, otras posteriores. 
cometida por una institución europea: el interés general justifica la comisión de algún yerro o contravención de la legalidad, sin que comporte consecuencias indemnizatorias, siempre que no se supere un determinado umbral de tolerancia.

En todo caso, hay que reconocer, por un lado, que la introducción de este requisito presenta aspectos positivos, pero también negativos (aunque ahora no procede detenerse en ellos) ${ }^{16}$; y, por otro lado, que su exigencia está muy firmemente establecida en el derecho de la Unión Europea, tanto para el caso de que el resarcimiento le corresponda a alguna institución de la Unión Europea (incumplidora), como para el caso que ahora nos ocupa, esto es, cuando el resarcimiento le corresponda a un Estado (incumplidor).

16 Entre los primeros, que propicia la coherencia misma del sistema, puesto que resultaba difícil de justificar el mantenimiento de dos «varas de medir»: una responsabilidad más estricta (y, por lo tanto, más dificultades para obtener la reparación), cuando tenía que indemnizar la Unión Europea y otra responsabilidad más amplia (y, por lo tanto más favorable al resarcimiento) cuando quienes tenían que indemnizar eran los Estados miembros. Además, la construcción teóricamente debía ser común y no ajena o extraña para nadie, porque la responsabilidad de la Unión se tiene que edificar — como es sabido - a partir de «los principios generales comunes a los derechos de los Estados miembros» (según establece el citado párrafo segundo del art. 340 TFUE); con lo cual, además, en último término era previsible que se produjese el conocido como efecto boomerang: el sistema existente en los ordenamientos de los Estados inspiraba el de la Unión y, luego (con esta S. Brasserie, precisamente), éste generaba en el ordenamiento de la Unión el sistema de responsabilidad de los Estados incumplidores.

Como aspectos negativos podemos señalar que la caracterización del incumplimiento como constitutivo de una violación suficientemente caracterizada no deja de ser una creación propia y muy específica del Tribunal de Justicia (a partir de su jurisprudencia de los años setenta y, sobre todo, ochenta), con los problemas que podía generar (y, de hecho, así ha sucedido) su interpretación y aplicación por los jueces estatales. También tenemos que tener en cuenta que el ámbito de actuaciones en el que se produce la responsabilidad de una (la Unión) y de otros (los Estados) es, respectivamente, diferente y extender a éstos lo previsto para aquélla puede llegar a resultar disfuncional (cosa que así se ha visto que podía suceder y que ha obligado, con el tiempo, a matizar el sistema, como veremos en seguida). En fin, si el propio concepto de violación suficientemente caracterizada, en su aplicación a la responsabilidad de la Unión, por las limitaciones que acarreaba, no había estado exenta de autorizadas críticas —así, el abogado general Léger, en las Conclusiones presentadas el 20 de junio de 1995, en el as. Hedley Lomas, C-5/94, se hizo favorable eco de las opiniones que consideraban el sistema de la responsabilidad ex 340 TFUE como «insatisfactorio, demasiado riguroso e insuficientemente protector del derecho a un recurso jurisdiccional efectivo» (aptdo. 145, cursiva en el original); por su parte, en las Conclusiones presentadas el 28 de noviembre de 1995 (aptdo. 63) a este as. Brasserie, el abogado general Tesauro no tendría reparo en decir que «esta jurisprudencia estableció requisitos tan restrictivos, especialmente en relación con la ilegalidad del comportamiento imputable a las instituciones, que dificulta extraordinariamente la condena de una institución comunitaria a la indemnización del daño»- era lógico prever que ahora se produjesen en relación al sistema de la responsabilidad de los Estados. Es más, el abogado general Léger, en las muy elaboradas Conclusiones recién citadas (aptdo. 111), propuso no que la responsabilidad de los Estados se recondujese a la de las instituciones de la Unión Europea (como así sucedería en Brasserie), sino al revés, que fuese la de éstas la que se aproximase a la que en aquel momento tenían los Estados y que era la establecida en Francovich (que, como sabemos, no incluía esta discutida limitación). 
B) El segundo aspecto a destacar se refiere a la autonomía recíproca existente entre, por un lado, el incumplimiento estatal de las obligaciones frente a la Unión y, por otro lado, el incumplimiento estatal que produce un daño a un particular (que es lo que aquí más interesa); ámbitos que conviene deslindar debidamente.

Así, para declarar la responsabilidad estatal no es precisa, de ninguna manera, la existencia previa de una Sentencia del Tribunal de Justicia que declare el incumplimiento ex art. 260 TFUE $^{17}$. Si existe un pronunciamiento previo declarativo del incumplimiento estatal, obviamente, será mucho más sencillo el reconocimiento de la responsabilidad, porque tendríamos adverado el requisito básico del incumplimiento. Pero no es un requisito imprescindible, puesto que, si se exigiera tal condición, se limitarían enormemente las posibilidades efectivas de reparación de los particulares (cuyo locus standi ante el Tribunal de Luxemburgo es limitadísimo en los recursos por incumplimiento, como es sabido ${ }^{18}$.

17 Esta apreciación encaja perfectamente en la perspectiva en la que el Tribunal de Justicia viene situando, desde mucho tiempo atrás, al derecho de la Unión. Así, a comienzos de los ochenta, refiriéndose expresamente a la función y cometidos del recurso por incumplimiento -y tras recordar que, en el caso de que la Sentencia declare la incompatibilidad con el Tratado de determinadas disposiciones legislativas de un Estado miembro, «ello supone, para las autoridades que participan en el ejercicio del poder legislativo, la obligación de modificar las disposiciones de que se trate, de manera que estas últimas sean conformes a las exigencias del derecho comunitario»-, afirmó con claridad que las sentencias dictadas en este tipo de proceso «tienen por objeto, en primer término, definir los deberes de los Estados miembros en caso de incumplimiento de sus obligaciones. Los derechos en favor de los particulares derivan de las disposiciones mismas del derecho comunitario que tengan un efecto directo en el ordenamiento jurídico interno de los Estados miembros» (Sentencia de 14 de diciembre de 1982, as. Waterkeyn, 314 a $316 / 81$ y $83 / 82$, aptdos. 14 y 15 , respectivamente).

18 En palabras del Tribunal: «la existencia de una sentencia anterior del Tribunal de Justicia en la que se declare el incumplimiento es un elemento sin duda alguna determinante, pero no indispensable para comprobar que se cumple dicho requisito»; y "supeditar la reparación del daño a la exigencia de una declaración previa, por parte del Tribunal de Justicia, de un incumplimiento del derecho comunitario imputable a un Estado miembro sería contrario al principio de efectividad del derecho comunitario, puesto que excluiría todo derecho a indemnización mientras el presunto incumplimiento no hubiera sido objeto de un recurso interpuesto por la Comisión en virtud del artículo [258 TFUE] y de una condena por parte del Tribunal de Justicia. Pues bien, los derechos a favor de particulares derivados de las disposiciones comunitarias que tienen efecto directo en el ordenamiento jurídico interno de los Estados miembros, no pueden depender de la apreciación por parte de la Comisión de la oportunidad de actuar, con arreglo al artículo [258 TFUE], en contra de un Estado miembro ni de que se dicte por el Tribunal de Justicia una eventual sentencia en la que se declare el incumplimiento» (S. Brasserie, cit. aptdos. 93 y 95).

En fin, tampoco estará de más completar lo anterior señalando que no sólo no es exigible un pronunciamiento previo del Tribunal de Justicia que declare el incumplimiento, sino tampoco una Sentencia previa de la que se deduzca el mismo, vía interpretación del Derecho de la Unión (esto es, dictada en virtud de lo previsto en el art. 267 TFUE). Nuevamente hay que decir que, si existe tal pronunciamiento, el incumplimiento estatal posterior será manifiesto, pero tampoco es imprescindible a efectos de obtención de la reparación. Recuérdese que ya en la $S$. Brasserie, también se precisaba que en cualquier caso, una violación es manifiestamente caracterizada cuando hubiera perdurado tras haberse dictado una sentencia prejudicial de la que se resulte la infracción estatal del ordenamiento de la Unión (aptdo. 57). 


\section{La extensión del principio al difícil ámbito del incumplimiento judi-} cial del derecho de la Unión Europea (2002)

La Sentencia Köbler ${ }^{19}$ completa el ciclo de construcción del principio de la responsabilidad patrimonial de los Estados por incumplimiento del derecho de la Unión Europea.

Aquí, el Tribunal de Justicia tiene que pronunciarse sobre la posible extensión de la obligación resarcitoria - y se adelanta que lo hará de manera afirmativa, aunque añadiendo algún matiz propio- a un tipo de incumplimiento estatal, el judicial, sobre el que previamente el Tribunal de Justicia aún no se había pronunciado nunca. Así como en Francovich y en Brasserie a sus elaboraciones sobre la responsabilidad estatal habían precedido sendas sentencias declaratorias del incumplimiento de los Estados respectivos, en Köbler eso no había ocurrido. Ya se ha indicado que la del incumplimiento y la del resarcimiento son vías autónomas y guiadas por lógicas diferentes, pero en las circunstancias señaladas, la construcción Köbler destaca aún más (y refuerza tal autonomía de pronunciamientos), puesto que, sin haber habido previamente ni una sola sentencia que hubiese declarado la existencia del incumplimiento de un Estado por una actuación jurisdiccional —se insiste—, va a establecer que también existe responsabilidad patrimonial por el incumplimiento judicial del ordenamiento de la Unión ${ }^{20}$.

Con referencia a la novedad que pudiera plantear este supuesto, el Tribunal de Justicia recordará el leitmotiv justificador de su construcción de la responsabilidad estatal, aplicándolo al caso: «Habida cuenta de la función esencial que desempeña el poder judicial en la protección de los derechos que los particulares deducen de las normas comunitarias, se mermaría la plena eficacia de dichas normas y se reduciría la protección de los derechos que reconocen si los particulares no pudieran obtener una indemnización, en determinadas condiciones, cuando sus derechos resulten lesionados por una violación del derecho comunitario imputable a una resolución de un órgano jurisdiccional de un Estado miembro que resuelva en última instancia» (aptdo. 33). Lo que remachará con un argumento específico: «A este respecto es preciso subrayar que un órgano jurisdiccional que resuelve en última instancia constituye por definición el último órgano ante el cual los particulares pueden alegar los derechos que les reconoce el ordenamiento jurídico comunitario. Dado que una violación de estos derechos por una resolución que ha

19 De 30 de septiembre de 2003, C-224/01, del Pleno del Tribunal.

20 En abstracto o de modo principial, se debe precisar; pues no la declaró para el caso concreto del Prof. Köbler, que era el planteado al Tribunal de Luxemburgo en la cuestión prejudicial que dio lugar a la Sentencia que nos ocupa. 
adquirido firmeza de un órgano jurisdiccional de ese tipo normalmente ya no puede ser rectificada, no se puede privar a los particulares de la posibilidad de exigir la responsabilidad del Estado con el fin de obtener por dicha vía una protección jurídica de sus derechos» (aptdo. 34) ${ }^{21}$.

Y, a todo ello, añade un nuevo e interesante factor o criterio de incumplimiento, cual es el de la omisión de la obligación de plantear la cuestión prejudicial (ex art. 267, párrafo tercero TFUE) por parte de los órganos jurisdiccionales nacionales que resuelvan en última instancia; si bien es verdad que no aporta precisión ulterior alguna para la determinación de cuándo existe — para este supuesto de incumplimiento de la obligación de plantear cuestión prejudicial, se insiste- una infracción manifiesta del Derecho de la Unión Europea constitutiva de una violación suficientemente caracterizada. Más recientemente, la Sentencia Ferreira da Silva ${ }^{22}$ ha confirmado la hipótesis planteada en Köbler, de tal manera que la indebida omisión (porque la interpretación del derecho de la Unión no estaba clara y, además, el tribunal nacional lo aplicó incorrectamente) vino a cualificar el incumplimiento estatal como constitutivo de una violación suficientemente caracterizada.

4. Relevancia del principio de la responsabilidad patrimonial de los Estados por su incumplimiento del derecho de la Unión Europea

De lo que acabamos de ver podemos concluir que la responsabilidad patrimonial del Estado - de la que, se insiste, no había un solo rastro en la letra del Tratado de la Comunidad Económica Europea; ni lo hay, hoy en día, en el vigente Tratado de Funcionamiento de la Unión Europeaaparece como principio del derecho de la Unión Europea relativamente tarde (en comparación con los otros grandes principios interordinamentales), puesto que no se formula por primera vez hasta finales de 1991, adquiriendo su definitiva consistencia en $1996^{23}$.

21 Como refuerzo argumentativo, esta Sentencia traerá a colación lo que sucede en el ámbito del Convenio Europeo para la protección de los Derechos Humanos, en donde el Tribunal de Estrasburgo puede condenar a un Estado a reparar los daños que un comportamiento contrario al citado Convenio haya producido a las personas perjudicadas, incluidos los supuestos imputables a los órganos jurisdiccionales nacionales que resuelven en última instancia (aptdo. 49).

22 De 9 de septiembre de 2015, C-160/14. Puede verse un comentario a la misma en E. CoBreros Mendazona (2016), «Un paso más en la consolidación de la responsabilidad patrimonial de los Estados por incumplimiento judicial del Derecho de la Unión Europea (y en el reforzamiento de la cuestión prejudicial): la Sentencia Ferreira da Silva», Revista Española de Derecho Europeo, 58, págs. 83 y ss.

${ }^{23}$ Moldeado, inicialmente, como una responsabilidad de tipo objetivo, en la que conscientemente se prescindió del requisito de la violación suficientemente caracterizada (como resulta de Francovich); posteriormente, se introdujo este requisito para hacer equivalente el sistema de la responsabilidad estatal al de la responsabilidad de las instituciones de la Unión 
La responsabilidad estatal de este tipo no tiene como objetivo la disuasión o la imposición de una sanción, sino la reparación de los daños sufridos por los particulares como consecuencia de las infracciones del derecho de la Unión Europea por parte de los Estados miembros. Procede precisarlo porque, a veces, se ha insistido en el supuesto carácter sancionatorio de esta construcción ${ }^{24}$. Pero conviene diferenciar bien, entonces, a) la responsabilidad de los Estados frente a las instituciones de la Unión en caso de incumplimiento de sus obligaciones derivadas del derecho de la Unión Europea, de b) la que surge ante los particulares perjudicados por tal hecho, que es la que aquí estamos considerando. Aquélla, a diferencia de ésta, no se activa por la lógica del resarcimiento ${ }^{25}$. Además, el incumplimiento estatal frente a la Unión es de carácter objetivo, pues se refiere a cualquier tipo de incumplimiento de las obligaciones contraídas en los Tratados, mientras que el destinado al resarcimiento requiere la existencia de otros requisitos específicos. En fin, los cauces jurídicos respectivos son radicalmente distintos: en el primer caso, el medio más usual es el proceso (declarativo) de incumplimiento (ex arts. 258 a 260 TFUE) ante el Tribunal de Justicia ${ }^{26}$; en el supuesto que ahora nos ocupa, su materialización habrá de efectuarse por las vías «internas» (esto es, las establecidas en y por cada Estado) para la reparación del daño así causado.

Europea cuando éstas incumplen su derecho y tienen un amplio margen de discrecionalidad, sobre todo en las actuaciones normativas (con Brasserie); y finalmente, se extendió la exigencia de la violación suficientemente caracterizada a todos los casos de incumplimiento, sin perjuicio de que, cuando no existe margen de apreciación, el mero incumplimiento ya pueda considerarse una violación suficientemente caracterizada (a partir de la Sentencia de 23 de mayo de 1996, as. Hedley Lomas, C-5/94; estadio en el que ahora estamos, por lo que a este requisito se refiere).

${ }^{24}$ Lo que en 1991 pudo, quizá, resultar algo más comprensible si se tiene en cuenta que las previsiones de la condena al pago de una suma a tanto alzado y/o multa coercitiva, prevista en el actual art. 260.2 TFUE —-para el Estado recalcitrantemente incumplidor_, no aparece hasta el Tratado de Maastricht (1992).

${ }^{25}$ Lo ha dicho con claridad el Tribunal de Justicia desde las dos ópticas:

A) «El procedimiento previsto en el artículo [260 TFUE], apartado 2, es un proceso judicial especial, propio del derecho comunitario, que no puede asimilarse a un proceso civil. La condena al pago de una multa coercitiva o de una suma a tanto alzado no tiene por objeto indemnizar el perjuicio que haya podido causar el Estado miembro de que se trate, sino ejercer una presión económica que le induzca a poner fin al incumplimiento declarado. Por consiguiente, las sanciones pecuniarias impuestas deben determinarse en función del grado de persuasión necesario para que dicho Estado miembro modifique su comportamiento" (Sentencia de 12 de julio de 2005, as. Comisión c. Francia, C-304/02, aptdo. 91).

B) «La responsabilidad de un Estado miembro basada en el derecho comunitario no tiene como objetivo la disuasión o la imposición de una sanción, sino la reparación de los daños sufridos por los particulares como consecuencia de las infracciones del derecho comunitario por parte de los Estados miembros» (Sentencia de 17 de abril de 2007, as. AGM-COS.MET, C-470/03, aptdo. 88).

26 En determinados supuestos seguido o acompañado de una condena a una multa coercitiva y/o a tanto alzado, en virtud de los apartados 2 y 3 del art. 260 TFUE. 
Este principio de la responsabilidad patrimonial de los Estados tiene el carácter de mínimo ${ }^{27}$, en el sentido de que debe ser respetado por los Estados, pero que puede ser mejorado por el ordenamiento de cada uno de ellos, de tal manera que no puede resultar de peor condición que el sistema «interno» de daños equivalente.

En fin, su concreción o materialización efectiva queda encargada a las jurisdicciones nacionales, aunque siempre presidida por los principios de equivalencia y efectividad, puesto que, si bien la jurisprudencia luxemburguesa reconoce que corresponde a cada ordenamiento estatal la fijación de los criterios que determinan la cuantía de la reparación, también advierte de que no podrán ser menos favorables que los referentes a reclamaciones semejantes basadas en el derecho estatal y que, en ningún caso, podrán articularse de manera que hagan prácticamente imposible o excesivamente difícil la reparación.

En todo caso, las jurisdicciones estatales siempre cuentan - como garantía de su correcta y acertada aplicación - con la inestimable ayuda de la cuestión prejudicial del art. 267 TFUE (que también en esta materia se ha mostrado decisiva).

\section{LA REPERCUSIÓN DE ESTE PRINCIPIO EN NUESTRO SISTEMA DE RESPONSA- BILIDAD}

\section{Su efectiva aplicación por la jurisdicción contencioso-administrativa}

En este apartado trataremos de mostrar cómo se ha recogido este nuevo título de imputación en nuestro sistema ${ }^{28}$. De entrada podemos afirmar que el análisis de la jurisprudencia existente muestra, sin lugar a dudas, que el principio de la responsabilidad patrimonial del Estado por incumplimiento del derecho de la Unión no ha resultado ni desconocido ni extraño para nuestros tribunales del orden contencioso-administrativo, que lo han tenido que venir aplicando desde hace ya algunos años ${ }^{29}$.

En efecto, el primer pronunciamiento (salvo error) en relación con este principio lo constituye una sentencia de la Audiencia Nacional de

27 De «estándar mínimo de protección» lo calificó el abogado general Léger en las Conclusiones al as. Hedley Lomas, cit., aptdo. 144, en expresión que ha hecho cierta fortuna.

${ }^{28}$ Para mayores precisiones, permítase la remisión a CoBreros Mendazona (2015: 127-239).

29 Como el propio Tribunal Supremo ha reconocido, un tanto enfáticamente, «no constituye novedad para este Tribunal asumir de forma clara la doctrina del Tribunal de Justicia de las Comunidades en relación con la responsabilidad objetiva del Estado por violación del derecho comunitario establecida a partir de la sentencia Francovich» [Sentencia del Tribunal Supremo de 14 de julio de 2010, rec. núm. 21/2008 (Ponente Picó)]. Aunque debe repararse en que esta referencia a la (supuesta) objetividad del sistema resarcitorio era correcta sólo al inicio (con Francovich y hasta Brasserie), pero ya no lo era, claramente, en el momento de dictarse esta Sentencia. 
$1998^{30}$, desestimatoria de una petición de indemnización formulada finalizando $1993^{31}$. Del Tribunal Supremo, la primera sentencia que resuelve directamente un recurso contencioso-administrativo sobre este tipo de pretensión indemnizatoria es un año posterior ${ }^{32}$.

Las dos primeras sentencias que conceden una indemnización de esta clase son de la Audiencia Nacional, de los años $2000^{33}$ y $2002^{34}$, respectivamente. Si bien la sentencia que ha sido siempre más destacada es la del Tribunal Supremo de 12 de junio de $2003^{35}$. Con posterioridad, se han producido numerosas sentencias estimatorias, que resultaría imposible mencionar aquí ${ }^{36}$.

Como vemos, las reclamaciones basadas en esta nueva causa indemnizatoria emergieron en nuestro panorama jurisprudencial de manera bastante temprana, correspondiendo a nuestra jurisdicción contencioso-administrativa la responsabilidad de su correcta resolución.

2. Una cuestión que ha planteado y solucionado el principio de equivalencia: la inicial diferencia de requisitos procedimentales para la indemnización de los daños causados por una ley inconstitucional y por una ley contraria al derecho de la Unión Europea

Desde su toma de postura en la Sentencia de 29 de enero de 200437, el Tribunal Supremo venía rechazando expresamente trasladar la cons-

30 Sentencia de la Audiencia Nacional de 24 de junio de 1998, rec. núm. 1287/1995 (ponente Mangas).

31 Dato temporal, este último, que se aporta para advertir de la rápida atención que la doctrina Francovich (noviembre de 1991, como ya sabemos) despertó en nuestro mundo jurídicoprofesional.

32 Sentencia del Tribunal Supremo de 10 de julio de 1999, rec. núm. 404/1995 (ponente Peces).

33 Sentencia de la Audiencia Nacional de 26 de enero de 2000, rec. núm. 37/1997 (ponente Mangas).

34 Sentencia de la Audiencia Nacional de 7 de mayo de 2002, rec. núm. 365/2001 (ponente Menéndez Rexach).

35 Rec. núm. 46/1999 (ponente Sieira). Llamativo y destacable pronunciamiento sobre todo por lo abultado de la indemnización concedida a la recurrente, Canal Satélite Digital SA (más de cuatro mil cuatrocientos millones de pesetas; si bien debe precisarse que tal cantidad constituía la cuarta parte de lo solicitado), y por las implicaciones político-mediáticas que tuvo el caso. El fundamento último del fallo estimatorio hay que buscarlo en la incorrecta incorporación al ordenamiento español de la Directiva sobre transmisión de señales de televisión (falta de corrección adverada por el propio Tribunal de Justicia en su Sentencia Canal Satélite Digital, de 22 de enero de 2002, C-390/99, contestando a la cuestión planteada por la Sala Tercera del Tribunal Supremo, precisamente). La Sentencia es extensísima, dedicando mucho espacio al tratamiento del derecho de la Unión, con manejo de primera mano de la jurisprudencia luxemburguesa, si bien también hay que reconocer que adolece de una cierta confusión en la prolijidad de sus planteamientos.

36 Valga con citar, por ejemplo, una de las más recientes, como es la Sentencia del Tribunal Supremo de 6 de mayo de 2016, rec. núm. 199/2014 (ponente Toledano).

37 Rec. núm. 52/2002 (ponente Sieira). 
trucción sobre la responsabilidad estatal por ley inconstitucional ${ }^{38}$ al caso de la responsabilidad estatal por ley incompatible con el derecho de la Unión ${ }^{39}$.

Dicho muy resumidamente, para el Tribunal Supremo, al contrario de lo que sucede con los actos de aplicación de una ley después declarada inconstitucional —en donde no puede considerarse una carga exigible al particular que, con la finalidad de eximirse de soportar los efectos de la inconstitucionalidad de una ley, tenga que recurrir un acto adecuado a la misma, aduciendo su inconstitucionalidad (por la presunción de constitucionalidad de que goza la ley y porque los particulares no son titulares de la acción de inconstitucionalidad $)^{40}$ - , en el caso de actos de aplicación de una ley después considerada incompatible con el derecho de la Unión Europea, el particular sí que era titular de una acción para invocar ante los tribunales la contradicción entre el ordenamiento estatal y el de la Unión - según la conocida construcción del principio de la primacía aplicativa del derecho supranacional- y, por lo tanto, podía (y debía) recurrir el acto de aplicación que considerara incumplidor del derecho de la Unión ${ }^{41}$.

La consecuencia de esta interpretación jurisprudencial era que, si no se había producido esa reacción (que podría haber reparado la indebida aplicación del precepto estatal y, con ella, el daño), con posterioridad

38 Elaborada por el Alto Tribunal a partir de dos importantes sentencias de 14 de diciembre de 2000 (recursos núm. 485/1998 y 486/1998, ponente Sieira); y seguida en otras muchas con posterioridad. Para esta construcción jurisprudencial, véase, por todos (con privilegiado conocimiento de causa), J. A. XIOL Ríos (2007), "La responsabilidad patrimonial por acto legislativo», en J. A. MoReno MARTínez (coord.), La responsabilidad civil y su problemática actual (espec. págs. 1065 y ss.), Madrid: Dykinson.

39 Relata el iter jurisprudencial N. Maurandi Guillén (2012), «La doctrina del Tribunal de Justicia de la Unión Europea sobre la responsabilidad del Estado legislador por violaciones del ordenamiento europeo. Su plena incorporación a la jurisprudencia española en las sentencias de 17 de septiembre de 2010 de la Sala Tercera del Tribunal Supremo (Recursos 373/3006, 149/2007, 153/2007)», en E. García de ENTERría y R. Alonso García (coords.), Administración y Justicia. (Un análisis jurisprudencial). Liber amicorum Tomás-Ramón Fernández, (vol. II, págs. 3381 y ss.), Madrid: Civitas.

${ }_{40}$ Véase, no obstante, lo que se dice al final de este trabajo en relación con la regulación establecida en la reciente Ley de Régimen Jurídico del Sector Público.

41 De aquí que, si no se había hecho esto último (recurrir el acto), la doctrina del acto firme y consentido, unida al principio de seguridad jurídica, se imponía y, a diferencia de lo establecido en las sentencias recaídas sobre ingreso indebido del gravamen complementario (en aplicación de una Ley declarada inconstitucional por el Tribunal Constitucional), al no impugnar el acta de conformidad, el recurrente estaba obligado a soportar el perjuicio irrogado por la aplicación de una Ley contraria al Derecho de la Unión. Consecuencia de todo ello será que, negando tanto la existencia de violación suficientemente caracterizada como la relación de causalidad, se desestimarían todas las pretensiones indemnizatorias basadas en el cobro indebido del IVA, realizado a partir de una ley española considerada incompatible con el derecho de la Unión (incompatibilidad constatada fehacientemente por el Tribunal de Justicia en su Sentencia de 21 de marzo de 2000, as. Gabalfrisa, C-110 y 147/98, y posteriormente en su Sentencia de 6 de octubre de 2005, as. Comisión c. España, C-204/03). 
no se podía pedir indemnización por el perjuicio sufrido a causa de la aplicación del acto basado en una ley incompatible con el derecho de la Unión. Todo ello a diferencia de lo ocurrido con los actos de aplicación de una ley declarada inconstitucional, que sí podían ser compensados ejerciendo la acción de indemnización en el plazo de un año desde la publicación de la Sentencia estimatoria de la inconstitucionalidad.

Esta interpretación — de la que hay que reconocer que, considerada aisladamente y atendiendo exclusivamente a las exigencias de nuestro ordenamiento interno, no carecía de fundamento- fue ampliamente criticada por sus consecuencias, ya que, en definitiva, suponía tratar las reclamaciones indemnizatorias ex iure europeo de una manera mucho más estricta que las que traían causa del ordenamiento constitucional propio.

En un momento dado, ante uno de los muchos asuntos que se le habían planteado recurriendo la negativa gubernamental a la indemnización solicitada por la aplicación de la ley española contraria a la Directiva, el propio Tribunal Supremo decidió "cuestionarse a sí mismo» ante el Tribunal de Justicia, requiriendo a éste sobre la compatibilidad de la interpretación y aplicación que acabamos de mencionar con los tan reiterados principios del ordenamiento de la Unión de equivalencia y de efectividad ${ }^{42}$.

Así se produce la conocida Sentencia Transportes Urbanos ${ }^{43}$, en la que el Tribunal de Luxemburgo llegará a la conclusión de que tal diferencia de régimen - esto es, el diverso tratamiento procedimental entre las indemnizaciones solicitadas con base en una ley posteriormente declarada inconstitucional (para las que la reclamación indemnizatoria tiene de plazo el año desde la publicación de la Sentencia del Tribunal Constitucional estimatoria del recurso o de la cuestión) y las solicitadas con base en una ley posteriormente constatada como incompatible con el derecho de la Unión Europea (para las que se requiere, en todo caso, la reacción dentro del año de producida la lesión, no computándose el plazo desde la Sentencia del Tribunal de Justicia) — resultaba incompatible con el principio de equivalencia.

El concreto y escueto razonamiento de la Gran Sala ${ }^{44}$ es que, teniendo las dos reclamaciones «exactamente el mismo objeto, a saber, la indemnización del daño sufrido por la persona lesionada por un acto o una omisión del Estado» (aptdo. 36), la única diferencia existente con-

42 Auto del Tribunal Supremo de 1 de febrero de 2008, rec. núm. 153/2007 (ponente Robles).

43 De 26 de enero de 2010, C-118/08.

44 Se extiende mucho más, en coincidente argumentación de fondo, el abogado general Poiares Maduro en sus Conclusiones cit., aptdos. 28 a 40. 
siste en qué Tribunal declara la infracción jurídica (aptdo. 43) y esta diferencia «no basta para establecer una distinción entre ambas reclamaciones a la luz del principio de equivalencia» (aptdo. 44).

A la vista de la interpretación efectuada por Luxemburgo en respuesta a su cuestión prejudicial, el Tribunal Supremo modificará expresamente $^{45}$ sus exigencias en los casos de responsabilidad patrimonial del Estado por incumplimiento del derecho de la Unión constatada con posterioridad a la relación jurídica donde se produce la lesión ${ }^{46}$, asimilándolas a los de responsabilidad patrimonial por ley inconstitucional, con lo que, en definitiva, se permitirá el ejercicio de la acción indemnizatoria ante el Consejo de Ministros en el plazo de un año desde que se publicó la Sentencia del Tribunal de Luxemburgo que declara incompatible la ley española con el derecho de la Unión.

Esta rectificación de rumbo tendrá destacada importancia si tenemos en cuenta que la mayoría de las solicitudes de indemnización fundamentadas en el incumplimiento del derecho de la Unión Europea se plantean, precisamente, para la reparación de los daños causados por la aplicación de leyes consideradas contrarias al derecho de la Unión Europea. Ahora bien, a estos efectos habrá de tenerse en cuenta lo dispuesto en la Ley de Régimen Jurídico del Sector Público, en los términos a los que haremos referencia al final de este trabajo.

\section{La discutida exigencia del requisito de la violación suficientemente caracterizada}

Las acciones de responsabilidad ejercitadas ante nuestra jurisdicción contencioso-administrativa se han venido formulando con fundamento en el principio de la responsabilidad patrimonial del Estado tal

45 En tres sentencias de 17 de septiembre de 2010, recursos 373/2006, 149/2007 y 153/2007 (ponente Lesmes).

46 Ésta fue su argumentación: «La respuesta prejudicial de la Sentencia de 26 de enero de 2010 del TJCE no ofrece duda: la doctrina de este Tribunal Supremo, resumida en el fundamento sexto, sobre la responsabilidad del Estado legislador en los casos de vulneración de la Constitución debe aplicarse, por el principio de equivalencia, a los casos de responsabilidad del Estado legislador por vulneración del derecho Comunitario. Ello obliga, por el principio de vinculación a que antes nos hemos referido, a rectificar la doctrina sentada en las sentencias de 29 de enero de 2004 y 24 de mayo de 2005, que entendieron que la no impugnación, administrativa y judicial, del acto aplicativo de la norma contraria al derecho Comunitario rompía el nexo causal exigido por la propia jurisprudencia comunitaria para la declaración de la responsabilidad patrimonial, ruptura que, como ya se expresó, no se admite en los casos de actos de aplicación de leyes inconstitucionales, casos en los que no es preciso el agotamiento de los recursos administrativos y jurisdiccionales para el ejercicio de la acción de responsabilidad» (STS de 17 de septiembre de 2010, cit.). 
y como se ha acuñado por el Tribunal de Luxemburgo y, así, intentando justificar la existencia de una violación suficientemente caracterizada (como hemos visto que se exige desde Brasserie). Sin embargo, desde hace algún tiempo se está planteando expresamente por diversos solicitantes que, dado que el sistema interno de responsabilidad patrimonial español no exige un requisito semejante, sino que es más "generoso», debiera eliminarse $-\mathrm{O}$, si se prefiere, quedar desplazada— la necesidad de justificar que el incumplimiento ha consistido, precisamente, en una violación suficientemente caracterizada (es decir, manifiesta o grave), dando preferencia al sistema estatal de responsabilidad patrimonial pública $^{47}$.

No podemos plantear aquí, con detalle, toda esta difícil cuestión ${ }^{48}$, pero sí podemos referir los aspectos más importantes.

Así, tanto el Consejo de Estado en la importante labor dictaminadora que le corresponde durante la tramitación administrativa de la acción indemnizatoria como el Tribunal Supremo resolviendo definitivamente los recursos contencioso-administrativos, aun con razonamientos diversos, han venido a coincidir en la necesidad de seguir exigiendo este requisito.

No parece, sin embargo, que ésta sea la opción interpretativa más acorde y coherente con el derecho de la Unión Europea, pero pronunciarse al respecto exige un análisis diferenciado de cada uno de los ámbitos en los que se produce la responsabilidad patrimonial (esto es, la responsabilidad del Estado legislador, del Estado juez y de las Administraciones públicas) y, luego, contrastarlo con el sistema supranacional basado en la tan repetida violación suficientemente caracterizada.

47 Debe recordarse aquí lo dicho al respecto por el Tribunal de Luxemburgo en las tres emblemáticas sentencias que aquí hemos mencionado:

A) En Francovich podemos leer: «Debe señalarse, además, que las condiciones de fondo y de forma establecidas por las diversas legislaciones nacionales en materia de indemnización de daños no pueden ser menos favorables que las referentes a reclamaciones semejantes de naturaleza interna» (aptdo. 43, la cursiva está añadida).

B) También en Brasserie se dice: «Los tres requisitos contemplados anteriormente son necesarios y suficientes para generar, a favor de los particulares, un derecho a obtener reparación, sin excluir, no obstante que, con arreglo al derecho nacional, el Estado pueda incurrir en responsabilidad en virtud de requisitos menos restrictivos» (aptdo. 66, la cursiva está añadida).

C) Asimismo, en Köbler se reitera de idéntica manera: «Los tres requisitos [...] son necesarios y suficientes para generar, a favor de los particulares, un derecho a obtener reparación, sin excluir, no obstante, que, con arreglo al Derecho nacional, el Estado pueda incurrir en responsabilidad en virtud de requisitos menos restrictivos» (aptdo. 57, la cursiva está añadida).

Con posterioridad, en otras muchas sentencias se ha ratificado en esta misma idea, con igual formulación.

48 Para un tratamiento más exhaustivo puede consultarse E. Cobreros Mendazona (2015), «La exigibilidad del requisito de la violación suficientemente caracterizada al aplicar en nuestro ordenamiento el principio de la responsabilidad patrimonial de los Estados por el incumplimiento del Derecho de la Unión Europea», en Revista de Administración Pública, 126, págs. 11 y ss. 
Tal análisis nos depara un panorama más complejo y matizado que podemos sintetizar así:

\section{A) Para el caso de la responsabilidad del legislador}

Conviene advertir que este supuesto es especialmente importante en el tema que nos ocupa porque la gran mayoría de las indemnizaciones solicitadas (y de las concedidas, podemos añadir) lo ha sido, como ya se ha apuntado, por reclamaciones planteadas tras la aplicación de leyes españolas contrarias al derecho de la Unión.

Pues bien, del análisis de la jurisprudencia del Tribunal Supremo para el caso de la responsabilidad patrimonial derivada de leyes inconstitucionales — que debe ser el tertium comparationis - se deduce, resumidamente, lo siguiente:

$\left.1^{\circ}\right)$ En todos los supuestos en los que ha reconocido la responsabilidad por la aplicación de una ley declarada posteriormente inconstitucional, le ha bastado con tal dato, sin ulteriores cualificaciones sobre la pura inconstitucionalidad. La propia Sala Tercera es perfectamente consciente de esta situación, pues ha reconocido de manera paladina que «la responsabilidad patrimonial del Estado por leyes declaradas inconstitucionales no exige, en principio, hacer ninguna valoración sobre la gravedad de la infracción de la Constitución ${ }^{49}$.

$2^{\circ}$ ) Más recientemente ha abierto la posibilidad de que, en circunstancias muy especiales (que aún no ha apreciado que se hayan producido en la realidad), los efectos de la inconstitucionalidad podrían tener que ser soportados por el perjudicado, con lo que «a diferencia de lo que ocurre con la violación del derecho de la Unión Europea, la gravedad de la infracción de la Constitución sólo excepcionalmente es relevante a efectos indemnizatorios» 50 .

En nuestro efectivo sistema jurisprudencial de responsabilidad por leyes inconstitucionales no se requiere, por tanto, cualificación alguna similar a la de la violación suficientemente caracterizada, con lo que su exigencia parece ir en contra de lo establecido por el Tribunal de Justicia de la Unión Europea.

49 «Mientras que la responsabilidad del Estado por violación del derecho de la Unión Europea tiene entre sus condiciones, como es bien sabido, que dicha violación sea suficientemente caracterizada» [Sentencia de 22 de septiembre de 2014, rec. núm. 390/2012 (ponente Díez-Picazo)].

50 Ibidem. 


\section{B) Para la responsabilidad judicial}

En el supuesto de incumplimiento del derecho de la Unión Europea imputable a un órgano jurisdiccional español que resuelve en última instancia (esto es, la construcción Kölber ya vista), la acción indemnizatoria habrá de tramitarse por el cauce del error judicial previsto en los arts. 292 y 293 LOPJ.

Como es harto sabido, sin embargo, esta posibilidad ha sido interpretada por el Tribunal Supremo de manera muy restrictiva, ya que sólo se produce el error judicial indemnizable ${ }^{51}$ en supuestos muy extremos ${ }^{52}$. Así, desde un principio - en fórmula que se repetirá hasta la fecha con muy ligeras variaciones-, el Tribunal Supremo viene exigiendo que «el yerro [judicial] debe ser palmario, patente, manifiesto, indudable e incontestable, de un modo objetivo y no tan sólo a ojos de quienes fueron parte o se sienten perjudicados» ${ }^{53}$; e incluso en muchas ocasiones utiliza expresiones aún más radicales, como cuando se refiere a resoluciones «esperpénticas, absurdas, que rompen la armonía del orden jurídico ${ }^{54}$. De tal manera que parece claro que los supuestos en los que nuestro Tribunal Supremo estaría dispuesto a apreciar un error judicial indemnizable en la interpretación o aplicación del derecho de la Unión son mucho más limitados o restringidos que los supuestos susceptibles de reparación patrimonial teorizados en Köbler (y basados en el carácter manifiesto del incumplimiento judicial, como ya sabemos).

Así, por ejemplo y destacadamente, con la jurisprudencia del Tribunal Supremo que tenemos hasta ahora, lo que el Tribunal de Justicia entiende por un desconocimiento manifiesto de su jurisprudencia -que constituye un incontestable supuesto de infracción manifiesta del derecho de la Unión ${ }^{55}$ - no parece que encaje fácilmente en los supuestos de error judicial que viene apreciando y declarando el Tribunal Supremo,

51 O «error cualificado» [Sentencia del Tribunal Supremo, Sala Cuarta, de 9 de febrero de 1998, rec. núm. 47/1997 (ponente Martín Valverde)] o «error en sentido técnico» [Sentencia del Tribunal Supremo, Sala Segunda, de 20 de noviembre de 1998, rec. núm. 390/1997 (ponente Martínez Menéndez)].

52 Pues «la concepción del "error judicial" es sumamente restrictiva», dirá por ejemplo la Sentencia de la Sala Tercera de 3 de diciembre de 1998, rec. núm. 557/1996 (ponente Rouanet), con plena conciencia de su estricta posición interpretativa.

53 Así lo expuso en la Sentencia del Tribunal Supremo, Sala Segunda, de 5 de octubre de 1987 (ponente Vivas), y así lo mantiene, por ejemplo, en la Sentencia del Tribunal Supremo, Sala Tercera, de 11 de marzo de 2009, rec. núm. 7/2008 (ponente Garzón).

54 Así se calificó en la Sentencia del Tribunal Supremo, Sala Primera, de 16 de junio de 1988 (ponente Carretero), y de la misma manera vuelve a expresarse, por ejemplo, en la Sentencia del Tribunal Supremo, Sala Tercera, de 2 de septiembre de 2014, rec. núm. 18/2013 (ponente Fernández Valverde).

55 S. Köbler, cit., aptdo. 56. 
por mucho que el adjetivo «manifiesto» se utilice por ambos tribunales, ya que, en la aplicación que hace este último, parece evidente que le otorga un contenido mucho más restrictivo que lo que el Tribunal de Luxemburgo considera que constituye una violación suficientemente caracterizada. El término (significante) es el mismo, pero su contenido (significado) difiere en uno y otro ámbito.

De todo ello surge, muy fundadamente, la duda sobre la compatibilidad de este sistema indemnizatorio, tal y como opera realmente, con el principio de efectividad, que es una exigencia reiteradamente establecida por el derecho de la Unión y que establece que las condiciones establecidas por las legislaciones nacionales no pueden articularse de manera que hagan "prácticamente imposible o excesivamente difícil obtener la indemnización».

En consecuencia, en los casos de reclamación de una indemnización por incumplimiento judicial del derecho de la Unión Europea, para cumplir con las exigencias de este último, el Tribunal Supremo deberá prescindir de su asentada y restrictiva jurisprudencia sobre el error judicial indemnizable para sustituirla por la aplicación pura y simple del requisito de la violación suficientemente caracterizada, según el contenido que le ha otorgado el Tribunal de Justicia, sobre todo en su S. Köbler.

\section{C) Para la responsabilidad administrativa}

Como está plenamente admitido, nuestro sistema de responsabilidad patrimonial de las Administraciones públicas ${ }^{56}$ está muy asentado sobre su caracterización como objetiva, esto es, sin necesidad de demostrar culpa alguna en el actuar administrativo (aunque sea éste el supuesto que, en la práctica, mayoritariamente la justifique), y basada en la antijuridicidad del daño producido, entendiendo ésta como la ausencia de deber jurídico de soportarlo (sin ulteriores cualificaciones). Cumplidos estos (y, obviamente, los restantes) requisitos, surge el derecho a ser íntegramente reparado por la lesión causada por la actuación (u omisión) administrativa ${ }^{57}$.

Así, pues, nuestro sistema de responsabilidad patrimonial de las Administraciones públicas no incorpora un requisito semejante al de la violación

\footnotetext{
56 Véase, por todas, la clásica exposición de E. García de EnTERría y T. R. Fernández RoDRÍGuEz (2015), Curso de Derecho Administrativo II, Madrid: Civitas-Thomson Reuters, $14^{\mathrm{a}}$ ed., págs. 357 y ss.

57 A este respecto, véase el clarificador trabajo de J. Leguina VILLA (2007), "Sobre el carácter objetivo de la responsabilidad de la Administración», en Revista Española de Derecho Administrativo, 136, págs. 669 y ss.
} 
manifiesta y grave del derecho, con lo que su exigencia - si es que se produce - también irá en contra de lo establecido por el Tribunal de Justicia.

\section{D) Conclusiones}

$1^{\text {a) }}$ Para la responsabilidad patrimonial en caso de leyes contrarias al derecho de la Unión Europea, no debe exigirse tampoco la cualificación de incumplimiento manifiesto y grave, como sinónimo de suficientemente caracterizado, por no ser éste un requisito que, para el Tribunal Supremo, tenga equivalente a la hora de otorgar la indemnización en los supuestos de leyes inconstitucionales.

$2^{a}$ ) Para las acciones indemnizatorias fundadas en un incumplimiento judicial del ordenamiento de la Unión, debe aplicarse el requisito de la violación suficientemente caracterizada, en detrimento de la interpretación propia del Tribunal Supremo sobre lo que (al menos hasta ahora) entiende por error judicial ex art. 293.1 LOPJ, por ser esta interpretación (estatal) más restrictiva que aquel requisito (europeo).

$3^{\text {a) }}$ Para las solicitudes de indemnización en caso de incumplimiento administrativo del derecho de la Unión, no debe exigirse el requisito de la violación suficientemente caracterizada por ser ésta una exigencia que no se requiere en el sistema interno de daños imputables a las Administraciones públicas y, por lo tanto, deberá aplicarse a aquel supuesto el sistema interno (más amplio o generoso).

\section{La regulación legal establecida por la Ley de Régimen Jurídico del Sector Público}

Recientemente el legislador (básico) ha terciado en la cuestión que se acaba de plantear al regular, por primera vez, el supuesto indemnizatorio por aplicación de normas contrarias al derecho de la Unión ${ }^{58}$. Así, el art. 32 de la Ley 40/2015, de Régimen Jurídico del Sector Público ${ }^{59}$ ha establecido lo siguiente:

5. Si la lesión es consecuencia de la aplicación de una norma declarada contraria al Derecho de la Unión Europea, procederá su indemnización cuando el particular haya obtenido, en cualquier instancia, sentencia firme desesti-

\footnotetext{
58 Lo que considera además, en su exposición de motivos, como una de las «novedades más destacables» en el ámbito de la responsabilidad patrimonial de las Administraciones públicas.

59 Con entrada en vigor diferida al 2 de octubre de 2016.
} 
matoria de un recurso contra la actuación administrativa que ocasionó el daño, siempre que se hubiera alegado la infracción del Derecho de la Unión Europea posteriormente declarada. Asimismo, deberán cumplirse todos los requisitos siguientes:

a) La norma ha de tener por objeto conferir derechos a los particulares.

b) El incumplimiento ha de estar suficientemente caracterizado.

c) Ha de existir una relación de causalidad directa entre el incumplimiento de la obligación impuesta a la Administración responsable por el derecho de la Unión Europea y el daño sufrido por los particulares.

De inmediato se advierte en esta regulación legal un doble aspecto de interés:

A) Por un lado, ahora se exige una previa actuación impugnatoria del particular interesado, que recurra el acto aplicativo de la norma (que, después, se constata contraria al derecho de la Unión), alegando precisamente la incompatibilidad de la norma estatal con el derecho supranacional; parece, pues, que se pretende que no se pueda solicitar la indemnización tras la declaración de una norma contraria al derecho de la Unión si antes no se hubiera reaccionado contra la misma.

No hay en eso diferencia alguna con el caso de la indemnización por leyes inconstitucionales, porque ahora también se establece el mismo requisito de la reacción previa para tal supuesto ${ }^{60}$.

B) Por otro lado, se incorpora ex lege el requisito de la violación suficientemente caracterizada.

De acuerdo con los dictámenes del Consejo de Estado y, sobre todo, con las sentencias del Tribunal Supremo, el legislador ha incluido expresamente el tan reiterado requisito. Sin embargo, para el supuesto de leyes inconstitucionales no se exige cualificación alguna a la inconstitucionalidad.

Esta diferencia de trato permite albergar serias dudas sobre su adecuación al derecho supranacional: bien por no respetar el principio de equivalencia (como se sostiene por algunos), bien por no respetar la prevalencia del derecho interno - establecida expresamente por el Tribunal de Justicia- cuando las condiciones de fondo o los requisitos sean menos restrictivos (como aquí se ha sostenido). Cuestión que podrá sol-

60 En efecto, en el apartado anterior de este artículo se establece lo siguiente: «4. Si la lesión es consecuencia de la aplicación de una norma con rango de ley declarada inconstitucional, procederá su indemnización cuando el particular haya obtenido, en cualquier instancia, sentencia firme desestimatoria de un recurso contra la actuación administrativa que ocasionó el daño, siempre que se hubiera alegado la inconstitucionalidad posteriormente declarada». 
ventarse si, en algún momento, el propio Tribunal Supremo pusiera en duda la compatibilidad de esta ley con el derecho de la Unión Europea y se lo preguntase al Tribunal de Justicia de Luxemburgo — cosa que, hoy por hoy, se antoja harto difícil, pero que nunca se puede descartar tajantemente que pueda suceder en el futuro (como hemos visto que pasó en el caso de la $S$. Transportes Urbanos)_, o si fuera algún Tribunal de Justicia de una comunidad autónoma el que se plantease la misma duda al tener que resolver una acción indemnizatoria basada en la aplicación de una ley autonómica contraria al derecho de la Unión. 
